\title{
Investigating changes in unintended pregnancies before and after the changes in the family planning policies in Iran: A multivariate decomposition analysis
}

\author{
Maryam Khoramrooz ${ }^{1}$, Aziz Rezapour*2, Shamsollah Shirinbakhsh ${ }^{3}$, Ardeshir Khosravi ${ }^{4}$ \\ Received: 13 Nov 2018 \\ Published: 12 Dec 2019
}

Abstract

Background: Unintended pregnancy is a global public health problem that has adverse health, economic, and social consequences for families and societies. This study aimed to measure levels of and analyze changes in unintended pregnancies before and after the changes in the family planning policies in Iran.

Methods: Data were extracted from Iran's Demographic and Health Surveys in 2000, 2010, and 2015. The study population consisted of married pregnant women aged 15-49 years. In this study, the data of 112 400, 29 609, and 32264 households and 4976, 1123, and 900 married pregnant women in 2000, 2010 and 2015, respectively, were used. Logistic regression model was applied to estimate effect of the study explanatory variables on unintended pregnancy in each year, and contribution of different factors to the changes in unintended pregnancies was investigated using multivariate decomposition method. All the study analyses were performed using the Stata software, with the statistical significance level of 0.05 .

Results: The rate of unintended pregnancies decreased by $13 \%$ in $2000-2010$ and by $1.3 \%$ in $2010-2015$. Changes in women's likelihood of experiencing unintended pregnancy positively contributed to unintended pregnancy reduction in 2000-2010 and 20102015; however, the change patterns were different. Changes in the distribution of women's characteristics had positive and negative contributions in 2000-10 and 2010-15, respectively. An increase in pregnant women's parity was the main factor with counteracting effect on unintended pregnancy reduction in 2010-2015.

Conclusion: Unintended pregnancies decreased among Iranian married women over the study years, but its reduction was slowed down after the changes in the family planning policies. Policy actions in health and other socioeconomic sectors aiming to encourage nulliparous women to become pregnant and help nulliparous women, women with the parity of more than 2 , and women in the middle and late reproductive ages to reduce their risk of unintended pregnancy, can accelerate the trend of unintended pregnancy reduction in the future.

Keywords: Unintended pregnancy, Public health, Family planning policy, Iran

Conflicts of Interest: None declared

Funding: Iran University of Medical Sciences (Grant No. IUMS/SHMIS 1395/9221504204)

*This work has been published under CC BY-NC-SA 1.0 license.

Copyright $\odot$ Iran University of Medical Sciences

Cite this article as: Khoramrooz M, Rezapour A, Shirinbakhsh Sh, Khosravi A. Investigating changes in unintended pregnancies before and after the changes in the family planning policies in Iran: A multivariate decomposition analysis. Med J Islam Repub Iran. 2019 (12 Dec);33:134. https://doi.org/10.47176/mjiri.33.134

\section{Introduction}

Unintended pregnancy is defined as a pregnancy that is unwanted or mistimed at the time of conception $(1,2)$. It

Corresponding author: Dr Aziz Rezapour, rezapour.a@iums.ac.ir

1. Department of Health Economics, School of Health Management and Information Sciences, Iran University of Medical Sciences, Tehran, Iran

2. Health Management and Economics Research Center, School of Health Management and Information Sciences, Iran University of Medical Sciences, Tehran, Iran

3. Department of Economics, University of Alzahra, Tehran, Iran

4. Deputy of Public Health, Ministry of Health and Medical Education, Tehran, Iran is considered a global public health problem that has adverse health, economic, and social consequences for both

$\uparrow$ What is "already known" in this topic:

According to the results of a meta-analysis, the rate of unintended pregnancies was $27.9 \%$ in the period of the family planning program implementation in Iran. Demographic and socioeconomic factors and women's contraception behaviors have had a significant association with unintended pregnancy.

$\rightarrow$ What this article adds:

Unintended pregnancies declined among Iranian married women during 2000-2015, but its reduction was slowed down after the changes in the family planning policies. An increase in pregnant women's parity was the main factor having a counteracting effect on unintended pregnancy reduction in this period. 
families and societies (3). In 2012, the rate of unintended pregnancies was estimated $40 \%$ worldwide; a half of these pregnancies led to abortions and the rest ended in miscarriages (13\%) and unplanned births (38\%) (4). It is possible to reduce unintended pregnancies through correct use of consistent and effective contraceptive methods (5). Expansion of contraceptive use in postrevolutionary era in Iran began with the introduction of the anti-natalist population policy and the Family Planning Program (FPP) in $1989(6,7)$. However, in the period of the FPP implementation, there was $17.4 \%$ unmet need for modern contraceptive methods (8). Also, $27.9 \%$ of the total pregnancies among women aged 15-44 years were unintended and $8.9 \%$ of every 1000 women aged $15-44$ years experienced induced abortions (9). In that period, a considerable proportion (about $75 \%$ ) of unintended pregnancies occurred in couples who have used contraceptive methods (10). In 2012, the government changed the population policies because of the low fertility rate in the country $(6,7)$. New policies were pro-natalist and the role of the Ministry of Health and Medical Education (MOHME) changed towards increasing the fertility rates through encouraging women to have 3 children by the age of 30 . In this period, providing free contraceptives was limited in the public sector and permanent sterilization was banned except for saving a person's life (7). Since unintended pregnancy is a complicated phenomenon and is affected by demographic and socioeconomic factors as well as couples' contraception behaviors (11-16), having a clear picture of its changes along with the changes in the government's Family Planning (FP) policies can help policymakers to identify subgroups of women that should be targeted for interventions to reduce such pregnancies in the future.

Previous studies have examined levels of unintended pregnancy and its related factors in Iran. These studies were done in particular geographic regions and/or in the periods of either the government's anti-natalist or pronatalist population policies in the country $(9,13,17-20)$. In this study, using a multivariate decomposition method, change in unintended pregnancies after the changes in the FP policies in Iran (2010-2015) was analyzed. Furthermore, a similar analysis was done on the implementation of the FPP over a span of 10 years (2000-2010). Finally, the results of 2 analyses were compared to discuss effects of the changes in the government's FP policies on the changes in unintended pregnancies among Iranian married women in reproductive ages.

\section{Methods}

\section{Data and study variables}

Data for this study were extracted from datasets of the Iran's Demographic and Health Survey (DHS) in 2000 conducted by the MOHME, and Iran's Multiple Indicator Demographic and Health Surveys (IrMIDHS) in 2010 and 2015 conducted by the MOHME and the National Institute of Health Research (NIHR). The study population consisted of married women aged 15-49 years who were pregnant at the time of the surveys. In this study, the data of 112 400, 29 609, and 32264 households and 4976, 1123 , and 900 married pregnant women, whose data in terms of the study variables had been collected completely in 2000, 2010, and 2015, respectively, were used. Survey sample weights were used in all analyses to obtain estimates that were representative of Iranian 15-49-year-old married pregnant women.

The outcome variable was pregnancy intention, which was binary and categorized as "intended" if woman wanted to be pregnant at the time of conception, and as "unintended" if, at the time of conception, woman either did not want to be pregnant at all (unwanted pregnancy) or did not want to be pregnant but wanted another child later (mistimed pregnancy). This standard definition for pregnancy intention had been applied in other studies as well $(14,16$, 21). Household's economic status was determined by the wealth index that was constructed using Principal Component Analysis (PCA) (22). Variables used in the PCA in 2000 included possession of television, radio, refrigerator, landline, motorcycle, car, bathroom, number of rooms per person, access to piped drinking water, and use of natural gas for cooking. Similarly, the possession of television, personal computer or laptop, refrigerator, washing machine, landline, motorcycle, car, bathroom, number of rooms per person, access to piped drinking water, access to internet, and use of natural gas for cooking were used in the PCA in 2010 and 2015. As the household's living standards have changed over time, 2 different sets of variables were selected for the wealth index construction in the study years. According to their wealth scores, household's economic status was divided into 5 categories as the poorest, poorer, middle, wealthier, and the wealthiest. Other study explanatory variables included age at pregnancy $(<20,20-34$ and 35-49 years), age at the first marriage $(<20,20-29$ and $>29$ years), parity $(0,1-2$, and $>2)$, household size, having a history of abortion or stillbirth (yes/no), place of residence (urban/rural), women's education level (illiterate, nonacademic, and academic), and contraceptive use before pregnancy (yes/no).

\section{Statistical analysis}

In this study, a descriptive analysis was first performed to compare the rates of unintended pregnancy and pregnant women's characteristics over the study years. Effect of the women's characteristics on unintended pregnancy was also estimated through logistic regression analysis. Then, contribution of the explanatory variables to the changes in the rate of unintended pregnancy was investigated using multivariate decomposition approach (23). The response function in decomposition analysis $(\mathrm{F})$, which was estimated following the logit regression, is as follows:

$P=F(X \beta)=\frac{e^{X \beta}}{1+e^{X \beta}}$

where $P$ represents a vector of predicted probabilities of unintended pregnancy, $X$ is a vector of the explanatory variables, and $\beta$ is a vector of the logit regression coefficients.

The decomposition method allows us to decompose changes in unintended pregnancy into 2 components: endowment and coefficient effects. The former is attributable to the changes in the characteristics of pregnant wom- 
en, provided that their likelihood of experiencing unintended pregnancy did not change over time; and the latter is attributable to the changes in the likelihood of experiencing unintended pregnancy, provided that pregnant women's characteristics did not change over time.

The decomposition analysis was done in overall and detailed forms. Overall decomposition was performed to identify total endowment and coefficient effects ( $E$ and $C$, respectively) of the explanatory variables on the changes in the rates of unintended pregnancy over the study years, which is as follows:

$$
\begin{aligned}
\bar{P}_{t}-\bar{P}_{t-n} & =\underbrace{\left\{F\left(\bar{X}_{t} \beta_{t}\right)-F\left(\bar{X}_{t-n} \beta_{t}\right)\right\}}_{E} \\
& +\underbrace{\left\{F\left(\bar{X}_{t-n} \beta_{t}\right)-F\left(\bar{X}_{t-n} \beta_{t-n}\right)\right\}}_{C}
\end{aligned}
$$

In the equation above, $t$ and $t-n$ are the comparison and reference years, which were 2010 and 2000 in the first decomposition analysis and 2015 and 2010 in the second analysis. $\bar{P}_{t}$ and $\bar{P}_{t-n}$ are means of the predicted probabilities of unintended pregnancy, $\bar{X}_{t}$ and $\bar{X}_{t-n}$ are means of the explanatory variables, and $\beta_{t}$ and $\beta_{t-n}$ are the logit regression coefficients in the years, $t$ and $t-n$, respectively.

In detailed decomposition, the endowment and coefficient effects of each explanatory variable $\left(E_{k}\right.$ and $C_{k}$, respectively) on the changes in the rate of unintended pregnancy over the study years were assessed using the equation below:

$$
\begin{aligned}
\bar{P}_{t}-\bar{P}_{t-n} & =E+C \\
& =\sum_{k=1}^{K} W_{\Delta X_{k}} E+\sum_{k=1}^{K} W_{\Delta \beta_{k}} C \\
& =\sum_{k=1}^{K} E_{k}+\sum_{k=1}^{K} C_{k}
\end{aligned}
$$

where $W_{\Delta X_{k}}$ and $W_{\Delta \beta_{k}}$ are the contributions of the $k$ th covariate to $E$ and $C$, respectively, calculated using the 2 following formulas:

$$
\begin{aligned}
& W_{\Delta X_{k}}=\frac{\beta_{t}^{k}\left(\bar{X}_{t}^{k}-\bar{X}_{t-n}^{k}\right)}{\sum_{k=1}^{K} \beta_{t}^{k}\left(\bar{X}_{t}^{k}-\bar{X}_{t-n}^{k}\right)} \\
& W_{\Delta \beta_{k}}=\frac{\bar{X}_{t-n}^{k}\left(\beta_{t}^{k}-\beta_{t-n}^{k}\right)}{\sum_{k=1}^{K} \bar{X}_{t-n}^{k}\left(\beta_{t}^{k}-\beta_{t-n}^{k}\right)}
\end{aligned}
$$

Where

$$
\sum_{k} W_{\Delta X_{k}}=\sum_{k} W_{\Delta \beta_{k}}=1.0
$$

$W_{\Delta X_{k}}$ is determined by the relative size of change in the mean of $k$ th covariate between 2 years weighted by the coefficient (effect) of this covariate in year $t$. Similarly, $W_{\Delta \beta_{k}}$ is determined by the relative size of change in the effect of $k$ th covariate between 2 years weighted by the mean of this covariate in year $t-n$. All the study anal- yses were performed using the Stata version 14 (24), with the statistical significance level of 0.05 .

\section{Results}

Table 1 demonstrates the summary statistics for pregnancy intention and characteristics of married pregnant women aged 15-49 years in 2000, 2010, and 2015. The rate of unintended pregnancies decreased by $13 \%$ in 2000 2010 (from $34.3 \%$ to $21.3 \%$ ) and by $1.3 \%$ in $2010-2015$ (from $21.3 \%$ to $20 \%$ ).

Among the explanatory variables, only the household size was continuous and not shown in Table 1 as the other categorical explanatory variables. The mean (SD) of the household size in 2000, 2010, and 2015 was 4.4 (2.6), 3.4 (1.9), and 3.5 (1.5), respectively. The average household size decreased in 2000-2010 by 1 person, whereas it increased by 0.1 person in $2010-2015$. As it is shown in Table 1, women's age at pregnancy increased over the study years. The age at the first marriage increased in 2000-2010 and remained almost unchanged in 2010-2015. Women's parity decreased in 2000-2010 and increased in 2010-2015. Having a history of abortion or stillbirth had a slight decrease in 2000-2010, but it increased in 20102015. Residence in urban areas increased and the pregnant women's education level improved over the study years. The households' economic status improved in 2000-2010, but there was a shift in the women's pregnancy from poorest, medium, and the wealthiest economic strata to the poorer and wealthier strata in 2010-2015. The contraceptive use before pregnancy decreased in 2000-2010, but it increased in 2010-2015.

Trends of the logistic regression odds ratios over the study years (Table 2) indicated that in most of the women's subgroups, an increase or decrease in the unintended pregnancy likelihood in 2000-2010 was followed by an adverse change in 2010-2015. Furthermore, there was a convergence in unintended pregnancy odds ratios within women's subgroups in 2015 compared to 2000 and 2010. In 2015, there was no statistically significant difference between most of women's subgroups in their likelihood of experiencing unintended pregnancy; it only increased significantly by an increase in the women's parity. However, in 2000 and 2010, in addition to the subgroups of women's parity, there was a significant difference in the likelihood of experiencing unintended pregnancy between most of other subgroups.

Table 3 indicates the results of the multivariate decomposition analysis. The overall decomposition results showed that unintended pregnancy reductions in 20002010 and 2010-2015 were largely attributable to the coefficient effects rather than the endowment effects. In 20002010 , the changes in endowments had positive (contributory) but lesser effects on unintended pregnancy reduction compared to the changes in coefficients. In 2010-15, contrary to the changes in coefficients, changes in endowments had negative (counteracting) effects on unintended pregnancy reduction. 
Table 1. Summary statistics for pregnancy intension and characteristics of married pregnant women aged 15-49 years in Iran during $2000-2015$

\begin{tabular}{|c|c|c|c|c|c|c|c|c|}
\hline \multirow[b]{2}{*}{ Women's characteristics } & \multicolumn{2}{|c|}{$2000(\mathrm{~N}=4976)$} & \multicolumn{2}{|c|}{$2010(\mathrm{~N}=1123)$} & \multicolumn{2}{|c|}{$2015(\mathrm{~N}=900)$} & \multirow{2}{*}{$\frac{2000-2010}{\text { Change }(\%)}$} & \multirow{2}{*}{$\frac{2010-2015}{\text { Change }(\%)}$} \\
\hline & $\mathrm{n}$ & $\%$ & $\mathrm{n}$ & $\%$ & $\mathrm{n}$ & $\%$ & & \\
\hline \multicolumn{9}{|l|}{ Pregnancy intention } \\
\hline Intended & 3251 & 65.7 & 881 & 78.7 & 720 & 80.0 & 13.0 & 1.3 \\
\hline Unintended & 1725 & 34.3 & 242 & 21.3 & 180 & 20.0 & -13.0 & -1.3 \\
\hline \multicolumn{9}{|l|}{ Age at pregnancy } \\
\hline$<20$ & 751 & 15.1 & 119 & 10.6 & 37 & 4.4 & -4.5 & -6.2 \\
\hline $20-34$ & 3810 & 76.6 & 878 & 78.2 & 684 & 73.2 & 1.6 & -5.0 \\
\hline $35-49$ & 415 & 8.3 & 126 & 11.2 & 179 & 22.4 & 2.9 & 11.2 \\
\hline$<20$ & 3190 & 64.1 & 556 & 49.8 & 465 & 49.3 & -14.2 & -0.5 \\
\hline $20-29$ & 1716 & 34.6 & 527 & 46.7 & 404 & 47.0 & 12.2 & 0.3 \\
\hline$>29$ & 70 & 1.3 & 40 & 3.5 & 31 & 3.7 & 2.2 & 0.2 \\
\hline \multicolumn{9}{|l|}{ Parity } \\
\hline 0 & 1913 & 40.4 & 529 & 47.2 & 217 & 24.3 & 6.8 & -22.9 \\
\hline $1-2$ & 1978 & 39.9 & 496 & 44.2 & 581 & 65.3 & 4.3 & 21.2 \\
\hline$>2$ & 1085 & 19.7 & 98 & 8.6 & 102 & 10.4 & -11.1 & 1.7 \\
\hline \multicolumn{9}{|c|}{ Having a history of abortion/stillbirth } \\
\hline Yes & 928 & 18.7 & 205 & 18.2 & 209 & 20.9 & -0.5 & 2.7 \\
\hline \multicolumn{9}{|l|}{ Place of residence } \\
\hline Rural & 2692 & 56.3 & 416 & 36.3 & 332 & 31.7 & -20.0 & -4.6 \\
\hline Urban & 2284 & 43.7 & 707 & 63.7 & 586 & 68.3 & 20.0 & 4.6 \\
\hline \multicolumn{9}{|l|}{ Women's education level } \\
\hline Illiterate & 1172 & 20.6 & 107 & 9.6 & 61 & 5.2 & -11.0 & -4.4 \\
\hline Nonacademic & 3524 & 73.2 & 863 & 76.7 & 681 & 76.4 & 3.5 & -0.2 \\
\hline Academic & 280 & 6.2 & 153 & 13.7 & 158 & 18.4 & 7.5 & 4.6 \\
\hline \multicolumn{9}{|c|}{ Household's economic status } \\
\hline Poorest & 1547 & 26.4 & 300 & 26.5 & 247 & 26.3 & 0.1 & -0.2 \\
\hline Poorer & 1265 & 23.9 & 266 & 23.3 & 234 & 25.3 & -0.6 & 2.0 \\
\hline Medium & 1038 & 20.7 & 223 & 20.0 & 161 & 17.0 & -0.7 & -3.0 \\
\hline Wealthier & 702 & 15.7 & 188 & 16.9 & 166 & 20.3 & 1.2 & 3.4 \\
\hline Wealthiest & 424 & 13.3 & 146 & 13.3 & 92 & 11.1 & 0.0 & -2.2 \\
\hline \multicolumn{9}{|c|}{ Contraceptive use before pregnancy } \\
\hline No & 2300 & 43.2 & 511 & 45.2 & 401 & 42.3 & 2.0 & -2.9 \\
\hline Yes & 2676 & 56.8 & 612 & 54.8 & 499 & 57.7 & -2.0 & 2.9 \\
\hline
\end{tabular}

Note. The n's are unweighted, but the percentages were calculated based on the sample weights in the surveys.

Table 2. Logistic regression adjusted odds ratios for unintended pregnancy among married pregnant women aged 15-49 years in Iran during 2000-2015

\begin{tabular}{|c|c|c|c|c|c|c|}
\hline \multirow[t]{2}{*}{ Women's characteristics } & \multicolumn{2}{|c|}{$2000(n=4976)$} & \multicolumn{2}{|c|}{$2010(n=1123)$} & \multicolumn{2}{|c|}{$2015(n=900)$} \\
\hline & Odds ratio & $95 \% \mathrm{CI}^{ \pm}$ & Odds ratio & $95 \% \mathrm{CI}$ & Odds ratio & $95 \% \mathrm{CI}$ \\
\hline \multicolumn{7}{|c|}{ Age at pregnancy $\left(\mathrm{RC}^{ \pm \pm}=20-34\right)$} \\
\hline$<20$ & $1.46^{*}$ & $(1.03,2.08)$ & $1.98^{*}$ & $(1.10,3.56)$ & 0.69 & $(0.21,2.27)$ \\
\hline $35-49$ & 1.39 & $(0.99,1.95)$ & $3.55^{*}$ & $(2.18,5.75)$ & 1.08 & $(0.54,2.16)$ \\
\hline \multicolumn{7}{|c|}{ Age at the first marriage $(\mathrm{RC}=$ under 20$)$} \\
\hline $20-29$ & 1.01 & $(0.81,1.27)$ & 1.14 & $(0.80,1.63)$ & 1.02 & $(0.61,1.71)$ \\
\hline$>29$ & $0.34^{*}$ & $(0.14,0.84)$ & $0.19^{*}$ & $(0.05,0.66)$ & 1.11 & $(0.32,3.82)$ \\
\hline \multicolumn{7}{|c|}{ Parity ( $\mathrm{RC}=$ having no live birth) } \\
\hline $1-2$ & $3.41^{*}$ & $(2.58,4.51)$ & $2.33^{*}$ & $(1.57,3.45)$ & $2.07^{*}$ & $(1.03,4.16)$ \\
\hline$>2$ & $9.94^{*}$ & $(6.93,14.24)$ & $3.93^{*}$ & $(2.02,7.67)$ & $4.02^{*}$ & $(1.47,11.00)$ \\
\hline Household size & $1.06^{*}$ & $(1.02,1.09)$ & 1.09 & $(0.99,1.19)$ & 1.15 & $(0.98,1.36)$ \\
\hline \multicolumn{7}{|c|}{$\begin{array}{l}\text { Having a history of abortion/stillbirth } \\
(\mathrm{RC}=\mathrm{No})\end{array}$} \\
\hline Yes & $0.77^{*}$ & $(0.61,0.97)$ & $0.60^{*}$ & $(0.39,0.92)$ & 0.87 & $(0.51,1.50)$ \\
\hline \multicolumn{7}{|c|}{ Place of residence $(\mathrm{RC}=$ rural $)$} \\
\hline \multicolumn{7}{|c|}{ Women's education level ( $\mathrm{RC}=$ illiterate $)$} \\
\hline Nonacademic & 1.11 & $(0.85,1.45)$ & 0.87 & $(0.51,1.51)$ & 2.47 & $(0.98,6.22)$ \\
\hline Academic & 0.70 & $(0.40,1.25)$ & 0.94 & $(0.41,2.13)$ & 1.70 & $(0.51,5.67)$ \\
\hline \multicolumn{7}{|c|}{ Household's economic status ( $\mathrm{RC}=$ poorest $)$} \\
\hline Poorer & 0.84 & $(0.66,1.07)$ & 0.93 & $(0.61,1.45)$ & 1.33 & $(0.65,2.72)$ \\
\hline Medium & $0.70^{*}$ & $(0.52,0.94)$ & $0.55^{*}$ & $(0.33,0.92)$ & 0.84 & $(0.38,1.86)$ \\
\hline Wealthier & $0.48^{*}$ & $(0.34,0.68)$ & 0.60 & $(0.35,1.03)$ & 0.82 & $(0.34,1.99)$ \\
\hline Wealthiest & $0.49^{*}$ & $(0.32,0.76)$ & $0.35^{*}$ & $(0.17,0.74)$ & 2.23 & $(0.83,5.99)$ \\
\hline \multicolumn{7}{|c|}{$\begin{array}{l}\text { Contraceptive use before pregnancy } \\
(\mathrm{RC}=\mathrm{No})\end{array}$} \\
\hline Yes & $1.97^{*}$ & $(1.62,2.39)$ & $2.56^{*}$ & $(1.81,3.61)$ & 1.03 & $(0.63,1.70)$ \\
\hline Constant & $0.09^{*}$ & $(0.06,0.14)$ & $0.07^{*}$ & $(0.03,0.17)$ & $0.03^{*}$ & $(0.00,0.01)$ \\
\hline
\end{tabular}

In the detailed decomposition, coefficient effects resulted from the changes in coefficients of the explanatory variables over the study years that are presented in terms of the odds ratios in Table 2. Coefficient effects showed that in 2000-10, a decline in the unintended pregnancy likelihood among women in the middle reproductive ages (aged 20-

\footnotetext{
4 http://mjiri.iums.ac.ir

Med J Islam Repub Iran. 2019 (12 Dec); 33:134.
} 
Table 3. Decomposition of changes in unintended pregnancy among married pregnant women aged 15-49 years during 2000-2010 and 2010-2015 in Iran

\begin{tabular}{|c|c|c|c|c|c|c|c|c|}
\hline & \multicolumn{4}{|c|}{$t=2010 t-10=2000$} & \multicolumn{3}{|c|}{$t=2015 t-5=2010$} & \\
\hline \multicolumn{9}{|l|}{ Overall decomposition } \\
\hline & \multicolumn{2}{|c|}{ Mean } & & & \multicolumn{2}{|c|}{ Mean } & & \\
\hline Unintended pregnancy $(t)$ & \multicolumn{2}{|c|}{0.2131} & & & \multicolumn{2}{|c|}{0.2002} & & \\
\hline Unintended pregnancy $(t-n)$ & \multicolumn{2}{|c|}{0.3429} & & & \multicolumn{2}{|c|}{0.2131} & & \\
\hline \multirow[t]{2}{*}{ Difference } & \multicolumn{2}{|c|}{-0.1298} & \multirow{2}{*}{\multicolumn{2}{|c|}{$\%$}} & \multicolumn{2}{|c|}{-0.0129} & & \\
\hline & \multicolumn{2}{|c|}{ Mean } & & & \multicolumn{2}{|c|}{ Mean } & \multicolumn{2}{|c|}{$\%$} \\
\hline Due to endowments & \multicolumn{2}{|c|}{$-0.0342^{*}$} & \multicolumn{2}{|c|}{26.3} & \multicolumn{2}{|c|}{$0.0319^{*}$} & \multicolumn{2}{|c|}{-248.0} \\
\hline Due to coefficients & \multicolumn{2}{|c|}{$-0.0956^{*}$} & \multicolumn{2}{|c|}{73.7} & \multicolumn{2}{|c|}{$-0.0448^{*}$} & \multicolumn{2}{|c|}{348.0} \\
\hline \multicolumn{9}{|l|}{ Detailed decomposition } \\
\hline Women's characteristics & Endowm & ffect & Coeffic & effect & Endown & effect & Coeffi & effect \\
\hline & Mean & $\%$ & Mean & $\%$ & Mean & $\%$ & Mean & $\%$ \\
\hline Age at pregnancy & & & & & & & & \\
\hline$<20$ & -0.0002 & 0.18 & -0.0029 & 2.3 & 0.0022 & -17.4 & -0.0082 & 63.6 \\
\hline $20-34$ & $-0.0016^{*}$ & 1.2 & $-0.0574^{*}$ & 44.3 & -0.0007 & 5.1 & 0.1496 & -1161.2 \\
\hline $35-49$ & $0.0027^{*}$ & -2.1 & $0.0079^{*}$ & -6.1 & 0.0026 & -20.1 & -0.0128 & 99.1 \\
\hline Age at the first marriage & & & & & & & & \\
\hline$<20$ & $-0.0112^{*}$ & 8.6 & 0.0190 & -14.1 & 0.0000 & -0.2 & -0.0708 & 549.4 \\
\hline $20-29$ & $0.0118^{*}$ & -9.1 & 0.0175 & -13.5 & 0.0000 & 0.1 & -0.0799 & 620.1 \\
\hline$>29$ & $-0.0039^{*}$ & 3.0 & -0.0011 & 0.8 & 0.0000 & -0.1 & 0.0110 & -85.1 \\
\hline Parity & & & & & & & & \\
\hline 0 & $-0.0076^{*}$ & 5.9 & $0.0319^{*}$ & -24.6 & $0.0220^{*}$ & -170.9 & 0.0037 & -28.8 \\
\hline $1-2$ & 0.0007 & -0.5 & 0.0040 & -3.1 & 0.0006 & -5.0 & -0.0096 & 74.3 \\
\hline$>2$ & $-0.0106^{*}$ & 8.1 & $-0.0175^{*}$ & 13.5 & $0.0016^{*}$ & -12.5 & 0.0012 & -9.2 \\
\hline Household size & $-0.0123^{\dagger}$ & 9.5 & 0.0229 & -17.7 & 0.0013 & -9.8 & 0.0503 & -390.8 \\
\hline $\begin{array}{l}\text { Having a history of } \\
\text { abortion/stillbirth }\end{array}$ & $0.0004^{*}$ & -0.3 & -0.0085 & 6.5 & -0.0005 & 3.8 & 0.0175 & -135.5 \\
\hline Residence in urban areas & 0.0021 & -1.6 & -0.0218 & 16.8 & 0.0014 & -10.5 & 0.0049 & -37.7 \\
\hline Women's education level & & & & & & & & \\
\hline Illiterate & -0.0011 & 0.8 & -0.0007 & 0.5 & 0.0028 & -22.1 & -0.0134 & 103.7 \\
\hline Nonacademic & -0.0003 & 0.3 & -0.0339 & 26.1 & -0.000 & 1.1 & 0.0967 & -750.7 \\
\hline Academic & 0.0000 & 0.0 & 0.0031 & -2.3 & 0.0003 & -2.5 & 0.0018 & -13.9 \\
\hline Household's economic status & & & & & & & & \\
\hline Poorest & $0.0000^{*}$ & 0.0 & 0.0021 & -1.6 & 0.0000 & -0.3 & -0.0394 & 306.1 \\
\hline Poorer & $-0.0003^{*}$ & 0.3 & 0.0068 & -5.2 & 0.0003 & -3.0 & -0.0141 & 109.8 \\
\hline Medium & 0.0002 & -0.1 & -0.0070 & 5.4 & 0.0013 & -9.8 & -0.0085 & 66.0 \\
\hline Wealthier & -0.0001 & 0.1 & 0.0077 & -5.9 & -0.0015 & 11.8 & -0.0118 & 91.4 \\
\hline Wealthiest & $0.0000^{*}$ & 0.0 & -0.0069 & 5.3 & -0.0019 & 15.1 & 0.0426 & -330.8 \\
\hline Contraceptive use before pregnancy & $-0.0029^{*}$ & 2.2 & 0.0270 & -20.9 & 0.0001 & -1.0 & -0.1273 & 989.0 \\
\hline Constant & & & -0.0879 & 67.7 & & & -0.0283 & 219.9 \\
\hline
\end{tabular}

34 years) and those with the parity of more than 2 had contributory effects on unintended pregnancy reduction by $44.3 \%$ and $13.5 \%$, respectively. In contrast, increased likelihood of unintended pregnancy among nulliparous women and those in the late reproductive ages (aged 3549 years) had counteracting effects on the total reduction of unintended pregnancy by $24.6 \%$ and $6.1 \%$, respectively. Trends of the changes in the likelihood of unintended pregnancy among these subgroups, except nulliparous women, were reversed and their unintended pregnancy likelihood changed insignificantly in 2010-2015. In this period, there was no characteristic with a significant coefficient effect on unintended pregnancy reduction by itself, but according to the results of the overall decomposition, the total changes in coefficients decreased unintended pregnancy by $4.5 \%$.

Endowment effects resulted from the changes in the distribution of pregnant women's characteristics over the study years that are described in Table 1. In this regard, changes in the women's parity was the main factor that had significant effects on unintended pregnancy reduction over the study years. In 2000-2010, increased pregnancies of nulliparous women and reduced pregnancies of those with the parity of more than 2 had contributory effects on unintended pregnancy reduction by $5.9 \%$ and $8.1 \%$, respectively. In contrast, in 2010-2015, a decline in nulliparous women's pregnancy and an increase in pregnancy of women with the parity of more than 2 had counteracting effects on unintended pregnancy reduction by $170.9 \%$ and $12.5 \%$, respectively.

\section{Discussion}

This study aimed to analyze the levels of and changes in unintended pregnancy as well as determinants of its changes from 2000 to 2015 in Iran. The study results showed that the rate of unintended pregnancies decreased by $14.3 \%$ over the study years. Much of this decline (13\%) occurred in 2000-2010 and a slight reduction in unintended pregnancies $(1.3 \%)$ was observed in 2010 2015.

According to the results of the overall decomposition analysis, changes in women's risk of unintended pregnancy was the main factor that significantly decreased the rate of unintended pregnancies in 2000-2010 and 2010-2015. Furthermore, in 2010-2015, following the changes in the FP policies, the rate of unintended pregnancies not only 
did not increase, but it also slightly decreased. However, unintended pregnancy reduction in 2010-2015 was slower than in 2000-2010 (an average annual reduction of 1.3\% in 2000-2010 and 0.3\% in 2010-2015). A slight difference was detected in the annual decline of unintended pregnancy following the changes in woman's risk of unintended pregnancy between 2000-2010 and 2010-2015 (an average annual reduction of $1 \%$ in $2000-10$ and $0.9 \%$ in $2010-15$ ). In contrast, there was a considerable difference between the 2 periods in the effect of the changes in pregnant women's characteristics (an average annual reduction of $0.3 \%$ in $2000-2010$ and an average annual increase of $0.6 \%$ in 2010-2015). In 2000-2010, the distributional changes aligned with the changes in the risk of unintended pregnancy decreased the rate of these pregnancies. In 2010-2015, however, a major part of unintended pregnancy reduction due to the changes in women's risk of unintended pregnancy was offset by the counteracting effect of the changes in characteristics of pregnant women.

Results of the detailed decomposition showed that in $2000-2010,57.8 \%$ of unintended pregnancy reduction was attributable to the reduced risk of unintended pregnancy among women in the middle reproductive ages and those with the parity of more than $2(44.3 \%$ and $13.5 \%$, respectively). Given that the reduction in unintended pregnancy in these women no longer continued after the changes in government's FP policies, it seems that in the period of the FPP implementation, free access to contraceptives as well as FP education and consultation in the public sector could help those women to improve their contraception behaviors. Behboudi-Gandevani et al found that in 2002-2011 the use of contraceptives (modern and traditional) was increased among women in reproductive ages in Tehran, Iran (25). Other studies also indicated that the probability of using contraceptives by women in the middle reproductive ages (26) and those with more children or childbirth $(27,28)$ was higher than their counterparts, suggesting that a decrease in unintended pregnancy risk in these women could be due to an increase in contraceptive use. After the changes in the FP policies, the trend of reduction in these women's risk of unintended pregnancy stopped and the rate of unintended pregnancy did not significantly increase among them. It seems that, limited access to free contraceptives in the public sector in 2010-2015 had no adverse effects on these women's contraception behaviors to practice their fertility preferences. However, more reduction of unintended pregnancy in women in the middle reproductive ages and those with the parity of more than 2, as it occurred in the period of the FPP implementation, can be a suitable policy option to further reduction of unintended pregnancies in the future.

An increment in the risk of unintended pregnancy among nulliparous women as well as women in the late reproductive ages in 2000-2010 indicated that presence of the FPP could not prevent from the increasing risk of unintended pregnancy in all women. The increased risk of unintended pregnancy in nulliparous women in 2000-2010 might have been due to their higher tendency to postpone childbearing because of their increased participation in education (29) or to achieve stable economic status and living standards and amenities $(30,31)$ that is a prerequisite for providing high quality child care (30). Findings of Erfani's study indicated that in 2000-2009, desire for remaining childless in nulliparous women was increased by 8 times in Tehran, Iran (13). Failure in nulliparous women's contraception might have been the reason for their increased risk of unintended pregnancy. According to the results of Erfani's study, women with lower parity were more likely to use withdrawals compared to the modern contraceptives (32). According the results of other studies, withdrawal users had a higher rate and probability of experiencing unintended pregnancies compared to modern contraceptives users $(10,17)$.

Similarly, increased risk of unintended pregnancy among those women in their late reproductive ages in 2000-2010 might have been due to changes in their fertility preferences. Women in higher maternal ages are more likely to have risky pregnancies $(33,34)$. Therefore, unintended pregnancy among them may increase due to their increased awareness of the possible consequences of being pregnant at older ages -under public education programs for FP within the government's anti-natalist population policies- (6) and their contraception failure in preventing from such pregnancies. As pointed out in Erfani's study, older women were more likely to use withdrawals over modern methods (32). Also, Nouhjah et al. indicated that about a half of the women over the age of 34 years used less effective contraceptive methods in Khuzestan, Iran (35), which could increase their contraception failure in preventing from unintended pregnancies $(10,17)$.

The risk of experiencing unintended pregnancies among nulliparous women and those in their late reproductive ages did not significantly increase after the changes in the FP policies. However, considering these women's increased risk of experiencing unintended pregnancies in the period of the FPP implementation, reducing their risk of unintended pregnancy can be an entry point for further reduction in these pregnancies in the future.

In addition to the changes in women's risk of unintended pregnancy, alterations in the distribution of pregnant women's characteristics also decreased unintended pregnancies during implementation of the FPP. However, after the changes in the FP policies, these changes had generally adverse effects on unintended pregnancy reduction. In 2000-2010, unintended pregnancies decreased mainly because of the reduction in women's parity, but after the changes in government's FP policies, pregnancy shifted from nulliparous women to those with the parity of 1-2 and more. Consequently, with regards to the lowest risk of unintended pregnancy in nulliparous women and the highest risk in those with the parity of more than 2 in 2015 , unintended pregnancy increased in that period. The reduction in nulliparous women's pregnancies in that period showed that contrary to the previous period of the FP implementation, these women were more successful in practicing their fertility preferences. Furthermore, Erfani showed that in 2000, women with more than 2 children who wanted to stop childbearing, were more likely to use modern contraceptive methods than withdrawals, and among these methods, female sterilization had the highest 
prevalence (27\%) (32). In 2010, female sterilization, with the prevalence of $14.15 \%$, was the second most common contraceptive method in Iran (36). In this regard, limited access to modern contraceptive methods in the public sector and banning permanent sterilization (7) might have been the reason for increased pregnancy and, consequently, unintended pregnancy among women with the parity of more than 2 after the changes in government's FP policies.

The present study had some limitations. First, as the data for this study were extracted from cross-sectional surveys, casualty between the outcome variable and the study explanatory variables should be interpreted with caution. Second, entering such variables as couples' employment, women's knowledge about contraceptive methods, type of contraceptive method, couples' agreement for pregnancy, and source of FP services, and cultural factors, such as religion and ethnicity into the study model can increase its explanatory power in showing variations of unintended pregnancy. In this study, it was not possible to determine the role of the above variables in the changes of unintended pregnancy due to the high rate of missing observations for some variables and limitations of the DHS questionnaires to gather related data over the study years for some others. Some of these data have not yet been collected in Iran's DHS programs and others were not in datasets of the 3 years. Despite these limitations, the strength of this study was that as it used data from 3 surveys with nationally representative samples, its findings can be generalized to all Iranian married women in their reproductive age.

\section{Conclusion}

In this study, it was found that unintended pregnancies decreased among Iranian women during 2000-2014, but its reduction was slowed down after the changes in the FP policies. An increment in women's parity was the main factor with a significant counteracting effect on unintended pregnancy reduction in 2010-2015. Given that in 2015 one-fifth of all pregnancies were unintended, it is necessary to organize appropriate policy actions in health and other socioeconomic sectors to encourage nulliparous women to become pregnant and help women with the parity of more than 2 to reduce their risk of experiencing unintended pregnancy. Furthermore, considering the different patterns of changes in women's risk of unintended pregnancy during implementation of the FPP and after its change, implementing appropriate policy actions to help nulliparous women and women in the middle and late reproductive ages to reduce their risk of experiencing unintended pregnancy can accelerate the trend of unintended pregnancy reduction in the future.

\section{Acknowledgment}

The authors thank the Ministry of Health and Medical Education (MOHME) for providing free access to the original data of 2000 DHS and 2010 IrMIDHS. The authors also extend their thanks to the Iran National Institute of Health Research (NIHR) for their support and for providing free access to the original data of 2015 IrMIDHS.

\section{Funding}

This study was part of a Ph.D. thesis supported by the Iran University of Medical Sciences (Grant No. IUMS/SHMIS 1395/9221504204) and it has been approved by the National Committee of Ethics in Biomedical Research (IR.IUMS.REC.1395.9221504204).

\section{Conflict of interests}

The authors have no conflict of interest to declare.

\section{References}

1. Exavery A, Kanté AM, Hingora A, Mbaruku G, Pemba S, Phillips JF. How mistimed and unwanted pregnancies affect timing of antenatal care initiation in three districts in Tanzania. BMC Pregnancy Childbirth. 2013;13(1):35.

2. Shah PS, Balkhair T, Ohlsson A, Beyene J, Scott F, Frick C. Intention to become pregnant and low birth weight and preterm birth: a systematic review. Matern Child Health J. 2011;15(2):205-16.

3. Yazdkhasti M, Pourreza A, Pirak A, Abdi F. Unintended pregnancy and its adverse social and economic consequences on health system: a narrative review article. Iran J Public Health. 2015;44(1):12-21.

4. Sedgh G, Singh S, Hussain R. Intended and unintended pregnancies worldwide in 2012 and recent trends. Stud Fam Plan. 2014;45(3):30114.

5. Calvert C, Baisley K, Doyle AM, Maganja K, Changalucha J, WatsonJones $\mathrm{D}$, et al. Risk factors for unplanned pregnancy among young women in Tanzania. J Fam Plan Reprod Health Care. 2013:1-12.

6. Aloosh M, Saghai Y. Birth control policies in Iran: a public health and ethics perspective. J Epidemiol Commun Health. 2016;70(6):529-33.

7. Karamouzian M, Sharifi H, Haghdoost AA. Iran's shift in family planning policies: concerns and challenges. Int J Health Policy Manag. 2014;3(5):231-3.

8. Motlaq ME, Eslami M, Yazdanpanah M, Nakhaee N. Contraceptive use and unmet need for family planning in Iran. Int J Gynaecol Obstet. 2013;121(2):157-61.

9. Shariati M. Induced abortion rate in Iran: a meta-analysis. Arch Iran Med. 2013;16(10):594 - 8.

10. Moosazadeh M, Nekoei-moghadam M, Emrani Z, Amiresmaili M. Prevalence of unwanted pregnancy in Iran: a systematic review and meta-analysis. Int J Health Plann Mgmt. 2014;29(3):e277-e90.

11. Calvert C, Baisley K, Doyle AM, Maganja K, Changalucha J, Watson-Jones D, et al. Risk factors for unplanned pregnancy among young women in Tanzania. J Fam Plann Reprod Health Care. 2013;39(4):e2.

12. Tebekaw Y, Aemro B, Teller C. Prevalence and determinants of unintended childbirth in Ethiopia. BMC Pregnancy Childbirth. 2014;14(1):326.

13. Erfani A. Levels, trends, and determinants of unintended pregnancy in iran: the role of contraceptive failures. Stud Fam Plann. 2013;44(3):299-317.

14. Ikamari L, Izugbara C, Ochako R, childbirth. Prevalence and determinants of unintended pregnancy among women in Nairobi, Kenya. BMC Pregnancy Childbirth. 2013;13(1):69.

15. Kassa N, Berhane Y, Worku A. Predictors of unintended pregnancy in Kersa, Eastern Ethiopia, 2010. Reprod Health. 2012;9(1):1.

16. Adhikari R, Soonthorndhada K, Prasartkul P. Correlates of unintended pregnancy among currently pregnant married women in Nepal. BMC Int Health Hum Rights. 2009;9(1):17.

17. Asadi Sarvestani K, Ahmadi A, Enayat H, Movahed M. Level and factors related to unintended pregnancy with a brief review of new population policies in Iran. Iran J Public Health. 2017;46(7):973-81.

18. Shahbazin S, Gholami A. Prevalence of unintended pregnancy and its related factors in Kermanshah, Kangavar city (west Iran). J Cummun Health Res. 2015;4(1):19-28.

19. Vakili M, Shahbazi H, Dehghan M. The prevalence of unintended pregnancies and its related demographic factors in hospitals of Yazd city-2008. Toloo-e-Behdasht. 2011;9(4):23-35. [In Persian]

20. Mohammadbeigi A, Mohammad Salehi N, Bayati A. Prevalence of unintended pregnancy and its related factors in Arak 2007. Koomesh 2009;10(3):201-6. [In Persian] 
21. Exavery A, Kanté AM, Njozi M, Tani K, Doctor HV, Hingora A, et al. Predictors of mistimed, and unwanted pregnancies among women of childbearing age in Rufiji, Kilombero, and Ulanga districts of Tanzania. Reprod Health. 2014;11(1):63.

22. Fry K, Firestone R, Chakraborty N. Measuring equity with nationally representative wealth quintiles. PSI, editor Washington, DC. 2014.

23. Powers DA, Yoshioka H, Yun M-S. mvdcmp: Multivariate decomposition for nonlinear response models. Stata J. 2011;11(4):55676.

24. StataCorp. 2015. Stata Statistical Software: Release 14. College Station, TX: StataCorp LP.

25. Behboudi-Gandevani S, Tehrani FR, Cheraghi L, Noroozzadeh M, Farahmand M, Azizi F. Trends of contraception use among married reproductive age women: Tehran lipid and glucose cohort study 20022011. Sex Reprod Healthc. 2017;12:116-22.

26. Tehrani FR, Farahani FKA, Hashemi M. Factors influencing contraceptive use in Tehran. Fam Pract. 2001;18(2):204-8.

27. Sadat-Hashemi SM, Ghorbani R, Majdabadi HA, Farahani FK. Factors associated with contraceptive use in Tehran, Iran. Eur J Contracept Reprod Health Care. 2007;12(2):148-53.

28. Asadi Sarvestani K, Khoo SL, Malek NM, Yasin SM, Ahmadi A. Determinants of Contraceptive Usage among Married Women in Shiraz, Iran. J Midwif Reprod Health. 2017;5(4):1041-52.

29. Lotfi R, Naeeni MR, Rezaei N, Farid M, Tizvir A. Desired numbers of children, fertility preferences and related factors among couples who referred to pre-marriage counseling in Alborz province, Iran. Int $\mathrm{J}$ Fertil Steril. 2017;11(3):211-9.

30. Moeeni M, Pourreza A, Torabi F, Heydari H, Mahmoudi M. Analysis of economic determinants of fertility in Iran: a multilevel approach. Int J Health Policy Manag. 2014;3(3):135-44.

31. Baki-Hashemi S, Kariman N, Ghanbari S, Pourhoseingholi M-A, Moradi M. Factors affecting the decline in childbearing in Iran: a systematic review. Adv Nurs Midwifery. 2018;27(3):11-9.

32. Erfani A. Factors associated with the use of withdrawal in Iran: Do fertility intentions matter? J Comp Fam Stud. 2012;43(2):301-12.

33. Fitzpatrick K, Tuffnell D, Kurinczuk J, Knight M. Pregnancy at very advanced maternal age: a UK population-based cohort study. BJOG. 2017;124(7):1097-106.

34. Pawde AA, Kulkarni MP, Unni J. Pregnancy in women aged 35 years and above: a prospective observational study. J Obstet Gynaecol India. 2015;65(2):93-6.

35. Nouhjah S, Amiri E, Khodai A, Yazdanpanah A, Baghu MN. Popular contraceptive methods in women aged 35 years and older attending health centers of 4 cities in Khuzestan province, Iran. Iran Red Crescent Med J. 2013;15(10):e4414.

36. Rashidian A, Khosravi A, Khabiri R, Khodayari E, Elahi E, Arab M, et al. Health observatory: first report I.R. Iran multiple-indicator demographic and health survey 2010. Tehran: Ministry of Health and Medical Education; 2012. [In Persian] 